\title{
STRUCTURE AND CHEMISTRY OF ORION S
}

\author{
Joseph P. McMullin, ${ }^{1}$ Lee G. Mundy, ${ }^{1}$ And Geoffrey A. Blake ${ }^{2}$ \\ Received 1992 June 1; accepted 1992 September 16
}

\begin{abstract}
We present interferometric observations of the SiO $J=2-1, \mathrm{H}^{13} \mathrm{CO}^{+} J=1-0, \mathrm{HC}_{3} \mathrm{~N} J=11-10, \mathrm{CH}_{3} \mathrm{OH}$ $J_{K}=2{ }_{0}-1_{0}$, and $\mathrm{SO}_{2} J_{K_{p} K_{o}}=8_{17}-8_{08}$ transitions along with the $\lambda=3.1 \mathrm{~mm}$ continuum toward the young stellar object Orion $\mathrm{S}$. The $\mathrm{HC}_{3} \mathrm{~N}$ and $\mathrm{H}^{13} \mathrm{CO}^{+}$emission trace similar spatial and velocity distributions which are extended and follow the Orion molecular ridge. The $\mathrm{SiO}$ emission is more spatially confined, peaking to the west of the $\lambda=3.1 \mathrm{~mm}$ continuum source, while the $\mathrm{CH}_{3} \mathrm{OH}$ emission peaks to the southwest. Weak $\mathrm{SO}_{2}$ emission was detected southeast of the continuum source position.

Column densities and fractional abundances are derived for each species at different positions in the region. In general, the molecular abundances near the continuum source are similar to those in the quiescent material near IRc 2, but the abundances decrease toward the continuum source position indicating localized depletions of at least a factor of 3 in our $\sim 10^{\prime \prime}$ beam. The presence of strong $\mathrm{SiO}$ emission with much weaker $\mathrm{SO}_{2}$ emission is interpreted as resulting from high-velocity shock interactions between the outflow from Orion $\mathrm{S}$ and the surrounding cloud. The apparent molecular depletions directly toward Orion S, and the similarity of abundances between the Orion $\mathrm{S}$ region and quiescent ridge material, suggest that Orion $\mathrm{S}$ is at an early stage of chemical evolution, prior to when substantial chemical differentiation occurs.
\end{abstract}

Subject headings: ISM: abundances - ISM : individual (Orion Nebula) - molecular processes radio lines: ISM

\section{INTRODUCTION}

The Orion IRc 2 region has played a central role in the study of the chemistry of star formation. Its proximity, brightness, and chemical complexity have provided valuable insights into many of the physical processes accompanying the birth of massive stars (Genzel \& Stutzki 1989; Blake et al. 1987). Molecular evaporation from dust grains (e.g., Plambeck \& Wright 1987; Walmsley et al. 1987), hydrogenation of molecules on grain sites (Blake et al. 1987), creation of molecules via high-temperatures reactions (e.g., Minh et al. 1990), and local modification of molecular abundances through interaction with stellar wind material (e.g., Vogel et al. 1984) are all thought to be occurring within $20^{\prime \prime}$ of IRc 2 . Studies of these processes have been greatly advanced through observations of molecular excitation, spatial distributions, and kinematics; but the physical and chemical complexity of the region has not made this an easy task. Ambiguities remain about the use of selected molecular tracers as unique signatures of grain evaporation, high-temperature shock chemistry, or changes in the atomic constituents of the gas (e.g., Prasad et al. 1987).

A young stellar object located 1'.5 to the south of IRc 2 in the OMC-1 molecular ridge, Orion S provides a second look at the chemistry of star formation in a region which should have had very similar prestellar physical conditions and abundances. Orion $\mathrm{S}$ was first identified as an active star formation region through measurements of $\mathrm{NH}_{3}(J, K)=(1,1)$ and $(2,2)$ lines (Ziurys et al. 1981) and through $400 \mu \mathrm{m}$ dust continuum maps (Keene, Hildebrand, \& Whitcomb 1982). Later measurements of $\mathrm{NH}_{3}$ indicated that this region, labeled $\mathrm{S} 6$, has gas kinetic temperatures as high as $270 \mathrm{~K}$ and represents a prominent maximum in $\mathrm{NH}_{3}$ emission distinct from IRc 2 (Batrla et al.

\footnotetext{
${ }^{1}$ Department of Astronomy, University of Maryland, College Park, MD 20742.

${ }^{2}$ Division of Geological and Planetary Sciences, California Institute of Technology 170-25, Pasadena, CA 91125.
}

1983; Mauersberger et al. 1986). Interferometer observations uncovered a compact dust emission source, with a size of $10^{\prime \prime} \times 4 "$ (Mundy et al. 1986), which coincided with peaks in the large-scale $\mathrm{NH}_{3}$ and CS $J=2-1$ emission (Batrla et al. 1983; Mundy et al. 1988). The millimeter continuum source is also coincident with the $\mathrm{C}^{\mathbf{1 8}} \mathrm{O}$ emission region labeled Peak 4 by Wilson et al. (1986), as well as the southern peak in $\lambda=1300 \mu \mathrm{m}$ (Schloerb, Snell, \& Schwartz 1987; Mezger, Wink, \& Zylka 1990) and $\lambda=870 \mu \mathrm{m}$ continuum maps (Mezger, Sievers, \& Zylka 1991). There is no centimeter wavelength emission directly identified with the millimeter source (Mundy et al. 1986). Due to strong IR emission from adjacent dust heated by the Trapezium stars, the mid-infrared to farinfrared flux from Orion $S$ has not been measured accurately and no near-infrared source has been detected within 3 " of the dust continuum peak (McCaughrean 1988, 1992). The total luminosity of the region is estimated to be $\sim 8.5 \times 10^{3} L_{\odot}$ (Drapatz et al. 1983; Mezger et al. 1990). Estimates of the overall mass of the molecular core in the Orion $\mathrm{S}$ region range from 50 to $140 M_{\odot}$ (Keene et al. 1982; Drapatz et al. 1983; Schloerb et al. 1987; Mezger et al. 1990).

Energetic outflow activity associated with Orion $\mathrm{S}$ has been observed in a number of molecular transitions. CO $J=2-1$ observations revealed a highly collimated bipolar outflow centered within $2^{\prime \prime}$ of the continuum peak, which extends $\sim 30^{\prime \prime}$ in the blue lobe and $120^{\prime \prime}$ in the red lobe at a position angle of $-30^{\circ}$ (Schmidt-Burgk et al. 1990). CO $J=7-6$ observations (Schmidt-Burgk et al. 1989) detected hot (500-1000 K) gas extending out $\sim 30 \mathrm{~km} \mathrm{~s}^{-1}$ from the ambient cloud velocity, centered on Orion $\mathrm{S}$. Thermal $\mathrm{SiO}$ emission, which is second in strength only to Orion IRc 2 (Ziurys, Friberg, \& Irvine 1989), shows a bipolar distribution with flux out to $\pm 12 \mathrm{~km}$ $\mathrm{s}^{-1}$ from line center (Ziurys, Wilson, \& Mauersberger 1990; Ziurys \& Friberg 1987).

In order to begin a more detailed study of the chemistry of Orion $\mathrm{S}$, we have mapped the region in transitions of $\mathrm{SiO}$, 
$\mathrm{SO}_{2}, \mathrm{H}^{13} \mathrm{CO}^{+}, \mathrm{HC}_{3} \mathrm{~N}$, and $\mathrm{CH}_{3} \mathrm{OH}$ along with the $\lambda=3.1$ mm continuum emission with the BIMA $^{3}$ array. The molecules were chosen to delineate the interaction of Orion $\mathrm{S}$ with its surroundings. For example, the $\mathrm{SiO}$ molecule is believed to have at least modest activation barriers which inhibit its formation in low-temperature gas, and its abundance is normally depressed by severe gas-phase depletions of Si (Blake et al. 1987). SiO may therefore arise preferentially in hightemperature regions (Ziurys et al. 1989) such as gas strongly shocked by outflowing material or strongly heated by radiation. $\mathrm{SO}_{2}$ also has relatively low abundance in normal cloud material due to a combination of depletion of gas-phase atomic oxygen and sulfur abundances (Prasad \& Huntress 1982; Blake et al. 1987) and perhaps some energy requirements (Mitchell 1984). Increased abundances of atomic species and higher gas temperatures are expected in regions of mild to strong interaction between an atomic rich outflow and ambient gas.

Methanol is thought to be enhanced when grain mantles are gently evaporated (Millar, Herbst, \& Charnley 1991); direct production in postshocked gas is unlikely. Regions of weak interaction between an outflow working surface and the surrounding ambient gas could provide environments in which sufficient energy is provided to liberate grain mantles without destroying the grains themselves. $\mathrm{HCO}^{+}$was theoretically predicted to be influenced by shock chemistry (Mitchell 1984); however, observations have revealed it to be an uncertain indicator of shocks and high-temperature chemistry (Ziurys et al. 1989; Rudolph \& Welch 1992). Comparison of the isotope $\mathrm{H}^{13} \mathrm{CO}^{+}$with other less ambiguous tracer molecules will help to clarify its role in the chemistry of star-forming regions. $\mathrm{HC}_{3} \mathrm{~N}$, whose abundance is relatively constant throughout the IRc 2 region (Blake et al. 1987), and the millimeter continuum emisson were chosen to trace the column density of the bulk of the material thus providing a standard for measuring relative enhancements.

In this paper, we report the results of these observations, compare the Orion $\mathrm{S}$ region with the region around IRc 2 and discuss possible implications for the chemistry of molecular cloud material in the vicinity of young, massive stars.

\section{OBSERVATIONS}

Spectral line and continuum data were obtained using two correlator setups of the three-element BIMA array between 1990 June and 1991 January. The molecular transitions observed and specifics of the correlator setups are provided in

${ }^{3}$ Berkeley, Illinois, and Maryland Association.
Table 1. Projected antenna spacings for the observations ranging from $2 \times 10^{3} \lambda$ to $4.5 \times 10^{4} \lambda$ were obtained in eight configurations for setup 1 and seven configurations for setup 2 , yielding synthesized beams of $13^{\prime \prime} \times 9^{\prime \prime}$ and $11^{\prime \prime} \times 6^{\prime \prime}$ with natural weighting and $8.5 \times 5^{\prime \prime} .5$ and $7^{\prime \prime} \times 4$.5 with uniform weighting, respectively. The pointing center position was $\alpha_{1950}=05^{\mathrm{h}} 32^{\mathrm{m}} 46^{\mathrm{s}} 0, \delta_{1950}=-05^{\circ} 26^{\prime} 01^{\prime \prime} .7$. At 86.847 and $100.076 \mathrm{GHz}$, the $6.1 \mathrm{~m}$ diameter antennas have primary beam widths of 2.3 and $2^{\prime} .0$, respectively.

The compact sources PK 0420 and $0605-085$ were used as phase calibrators. The flux scale was established from observations of Mars and Venus using the brightness temperatures given by Ulrich (1981). PK 0420 was adopted as a secondary calibration standard with a flux density of $5.1 \mathrm{Jy}$ at both 86 and $100 \mathrm{GHz}$. Observations of $3 \mathrm{C} 84$ were used to calibrate the passband. The single-sideband system temperature during the observations was generally $\sim 600 \mathrm{~K}$ scaled to outside the atmosphere.

For each correlator setup, a line-free continuum map was formed by averaging the channels in a correlator band showing no line emission. The dirty continuum maps were subtracted from the dirty spectral line maps, then the data were CLEANed using the MIRIAD data reduction package developed by BIMA. Natural weighting maps were favored due to the extended nature of the observed emission. Typical rms noise values for the cleaned maps are given in the last column of Table 1. No correction for primary beam taper has been applied.

Broad-band continuum data were obtained simultaneously with the spectral line data using the analog correlator $(\Delta v \sim 140 \mathrm{MHz})$. The flux in these data is dominated by freefree emission from the Orion $\mathrm{H}$ II region, M42. In order to better highlight the dust component at millimeter wavelengths, the $\lambda=2 \mathrm{~cm}$ map of the region from Mundy et al. (1986) was scaled assuming optically thin emission and subtracted from the BIMA data using the method outlined by Wright et al. (1992).

\section{RESULTS}

Integrated intensity maps for the five observed molecular species and the residual continuum flux at $96.7 \mathrm{GHz}$ are shown in Figure 1. All channels with $4 \sigma$ or greater emission were included in the integrated intensity maps; for $\mathrm{SO}_{2}$ and $\mathrm{SiO}$, the emission was integrated from 4.5 to $10.1 \mathrm{~km} \mathrm{~s}^{-1}$. The $\mathrm{SiO}$ $J=2-1$ transition shown in the top left panel exhibits compact emission centered west and a little south of the Orion $\mathrm{S}$ millimeter continuum source (triangle) and a weaker extension off to the north. The strong emission near the top of the panel is associated with IRc 2 (square). For $\mathrm{H}^{13} \mathrm{CO}^{+}$, the $J=1-0$ emis-

TABLE 1

ObSERVED TRANSitions

\begin{tabular}{|c|c|c|c|c|c|}
\hline Transition & $\begin{array}{l}\text { Rest } \\
\text { Frequency } \\
{[\mathrm{GHz}]}\end{array}$ & $\begin{array}{l}\text { Correlator } \\
\text { Setup }\end{array}$ & $\begin{array}{l}\text { Channel } \\
\text { Width } \\
\left(\mathrm{km} \mathrm{s}^{-1}\right)\end{array}$ & $\begin{array}{l}\text { Velocity } \\
\text { Coverage } \\
\left(\mathrm{km} \mathrm{s}^{-1}\right)\end{array}$ & $\begin{array}{l}\text { rms Noise in } \\
\text { CLEAN Maps } \\
\text { (Jy beam }{ }^{-1} \text { ) }\end{array}$ \\
\hline 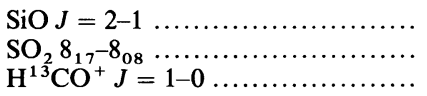 & $\begin{array}{l}86.847 \\
83.688 \\
86.754\end{array}$ & $\{1$ & $\begin{array}{l}0.27 \\
0.28 \\
0.14\end{array}$ & $\begin{array}{l}34.5 \\
35.8 \\
17.3\end{array}$ & $\begin{array}{l}0.5 \\
0.5 \\
0.5\end{array}$ \\
\hline $\begin{array}{l}\mathrm{HC}_{3} \mathrm{~N} J=11-10 \ldots \ldots \ldots \ldots \ldots \ldots \\
\mathrm{CH}_{3} \mathrm{OH} 2_{-1}-1{ }_{-1} E \ldots \ldots \ldots \ldots \ldots \ldots \\
\mathrm{CH}_{3} \mathrm{OH} 2_{0}-1_{0} A^{+} \ldots \ldots \ldots \ldots \ldots \ldots \ldots \\
\mathrm{CH}_{3} \mathrm{OH} 2_{0}-1_{0} E \ldots \ldots \ldots \ldots \ldots \ldots \ldots \ldots\end{array}$ & $\begin{array}{r}100.076 \\
96.739 \\
96.741 \\
96.744\end{array}$ & $\{2$ & $\begin{array}{l}0.12 \\
0.12 \\
0.12 \\
0.12\end{array}$ & $\begin{array}{l}15.0 \\
15.5 \\
15.5 \\
15.5\end{array}$ & $\begin{array}{l}0.64 \\
0.5 \\
0.5 \\
0.5\end{array}$ \\
\hline
\end{tabular}




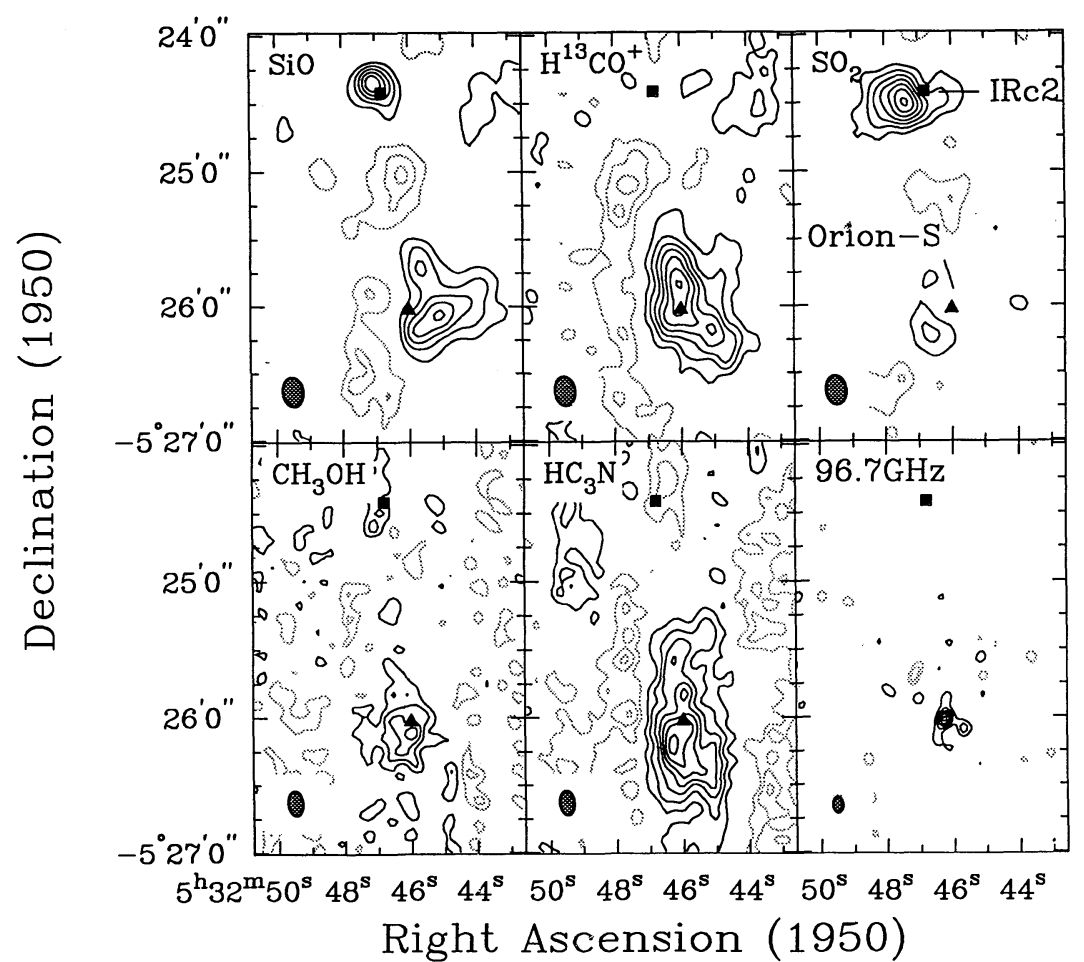

FIG. 1.- Integrated intensity maps. The contour levels are in steps of 3.3 for SiO, 2.4 for $\mathrm{H}^{13} \mathrm{CO}^{+}, 3.4$ for $\mathrm{SO}_{2}, 2$ for $\mathrm{CH}_{3} \mathrm{OH}$, and $3.4 \mathrm{Jy} \mathrm{km} \mathrm{s}{ }^{-1}$ for $\mathrm{HC}_{3} \mathrm{~N}$. For the $96.7 \mathrm{GHz}$ continuum, contours are in steps of \pm 0.05 starting at $0.1 \mathrm{Jy}$. The triangle marks the position of the peak continuum (Orion $\mathrm{S}$ ); the square marks the position of IRc 2. The beams for each observations are represented in the lower left column of the panel. The molecular line maps have been continuum subtracted (see § 2.)

sion shown in the top center panel has a north-south elongated structure which peaks north of Orion $S$ and has a weaker extension to the southwest overlapping the main $\mathrm{SiO}$ emission region. The multiple negative contours in the $\mathrm{SiO}$ and $\mathrm{H}^{13} \mathrm{CO}^{+}$maps are the result of emission on larger spatial scales than those sampled by our observations. As shown in the top right panel, strong $\mathrm{SO}_{2}$ emission was detected from the IRC 2 region, but only weak $(\sim 4 \sigma)$ emission is seen in the vicinity of Orion $\mathrm{S}$. It is important to note that the IRc 2 region lies just beyond the half-power point of the primary beam in these observations. Consequently, the emission from the IRc 2 region is not accurately portrayed in our maps.

The lower left and lower center panels in Figure 1 display maps of the $\mathrm{CH}_{3} \mathrm{OH}$ and $\mathrm{HC}_{3} \mathrm{~N}$ emission, respectively. All three observed transitions of $\mathrm{CH}_{3} \mathrm{OH}$ show the same compact emission centered south of Orion $\mathrm{S}$. The $\mathrm{HC}_{3} \mathrm{~N}$ emission shows a strong north-south elongated structure which is peaked south of Orion $\mathrm{S}$ but extends north into the main $\mathrm{H}^{13} \mathrm{CO}^{+}$emission region. Again, the strong negative contours in the map are the result of missing flux on larger spatial scales; observations of the $\mathrm{HC}_{3} \mathrm{~N} J=12-11$ transition by MartinPintado, Rodriguez-Franco, \& Bachiller (1990) confirm the presence of the large-scale emission. Finally, the lower right panel shows the $96.7 \mathrm{GHz}$ continuum flux after the extrapolated ionized gas emission from M42 has been subtracted. The continuum emission is compact and peaked on the position previously given by Mundy et al. (1986). The total continuum flux from Orion $\mathrm{S}$ is $680 \mathrm{mJy}$ at $96.7 \mathrm{GHz}$. Emission from the IRc 2 region is only marginally detected in the lower row of maps due to the smaller primary beam at 96.7 and $100.1 \mathrm{GHz}$.
Table 2 lists the peak flux, integrated intensity, and position offset between the line peak and continuum peak. Figure 2 shows the spectra for each molecule at the position of the continuum peak (left column), the $\mathrm{SiO}$ peak (center column), and the emission peak in each molecule (right column). The velocity extent of the molecular emission is less than $7 \mathrm{~km} \mathrm{~s}^{-1}$ with the exception of the $\mathrm{SiO}$ emission which displays line wings extending over $\sim 14 \mathrm{~km} \mathrm{~s}^{-1}$. As can be seen from the line channel maps in Figure 3, the SiO emission is spatially segregated with the blueshifted emission predominantly to the northeast and the redshifted emission predominantly to the southwest of Orion $\mathrm{S}$. The opposite velocity pattern is barely discernible from the channel maps of $\mathrm{H}^{13} \mathrm{CO}^{+}$shown in Figure 4. There is no detectable velocity pattern to the $\mathrm{HC}_{3} \mathrm{~N}$ emission. The methanol emission is quite narrow, centered about

TABLE 2

MoleCUlar EMisSion toward ORION S

\begin{tabular}{|c|c|c|c|}
\hline Transition & $\begin{array}{c}S_{\text {peak }}^{\mathrm{a}} \\
\left(\mathrm{Jy} \mathrm{beam}^{-1}\right)\end{array}$ & $\begin{array}{c}\int S_{\text {peak }} d V^{\mathrm{a}} \\
\left(\mathrm{Jy} \text { beam }^{-1} \mathrm{~km} \mathrm{~s}^{-1}\right)\end{array}$ & $\begin{array}{l}\text { Offset }^{\mathrm{b}} \\
\left({ }^{\prime \prime}\right)\end{array}$ \\
\hline $\mathrm{SiO} J=2-1$ & 6.54 & 17.2 & $18^{\prime \prime} \mathrm{W} / 2^{\prime \prime} \mathrm{S}$ \\
\hline $\mathrm{SO}_{2} 8_{17}-8_{08} \ldots \ldots$ & 2.7 & 7.6 & $6^{\prime \prime} \mathrm{E} / 12^{\prime \prime} \mathrm{S}$ \\
\hline $\mathrm{H}^{13} \mathrm{CO}^{+} J=1-0 \ldots \ldots$ & 5.66 & 17.0 & $4^{\prime \prime} \mathrm{W} / 12^{\prime \prime} \mathrm{N}$ \\
\hline $\mathrm{HC}_{3} \mathrm{~N} J=11-10 \ldots \ldots$ & 6.73 & 25.2 & $4^{\prime \prime} \mathrm{E} / 10^{\prime \prime} \mathrm{S}$ \\
\hline $\mathrm{CH}_{3} \mathrm{OH} 2_{0}-1_{0} E \ldots \ldots$ & 3.19 & 9.2 & $4^{\prime \prime} \mathrm{W} / 6^{\prime \prime} \mathrm{S}$ \\
\hline
\end{tabular}

${ }^{a}$ Emission in a natural weighted beam, $13^{\prime \prime} \times 9^{\prime \prime}$ for $\mathrm{H}^{13} \mathrm{CO}^{+}$and $\mathrm{SiO}$, $11^{\prime \prime} \times 6^{\prime \prime}$ for $\mathrm{HC}_{3} \mathrm{~N}$ and $\mathrm{CH}_{3} \mathrm{OH}$.

${ }^{b}$ Offset relative to millimeter continuum source, $\alpha_{1950}=05^{\mathrm{h}} 32^{\mathrm{m}} 46^{\mathrm{s}} .13$; $\delta_{1950}=-05^{\circ} 26^{\prime} 01^{\prime \prime} 7$. 


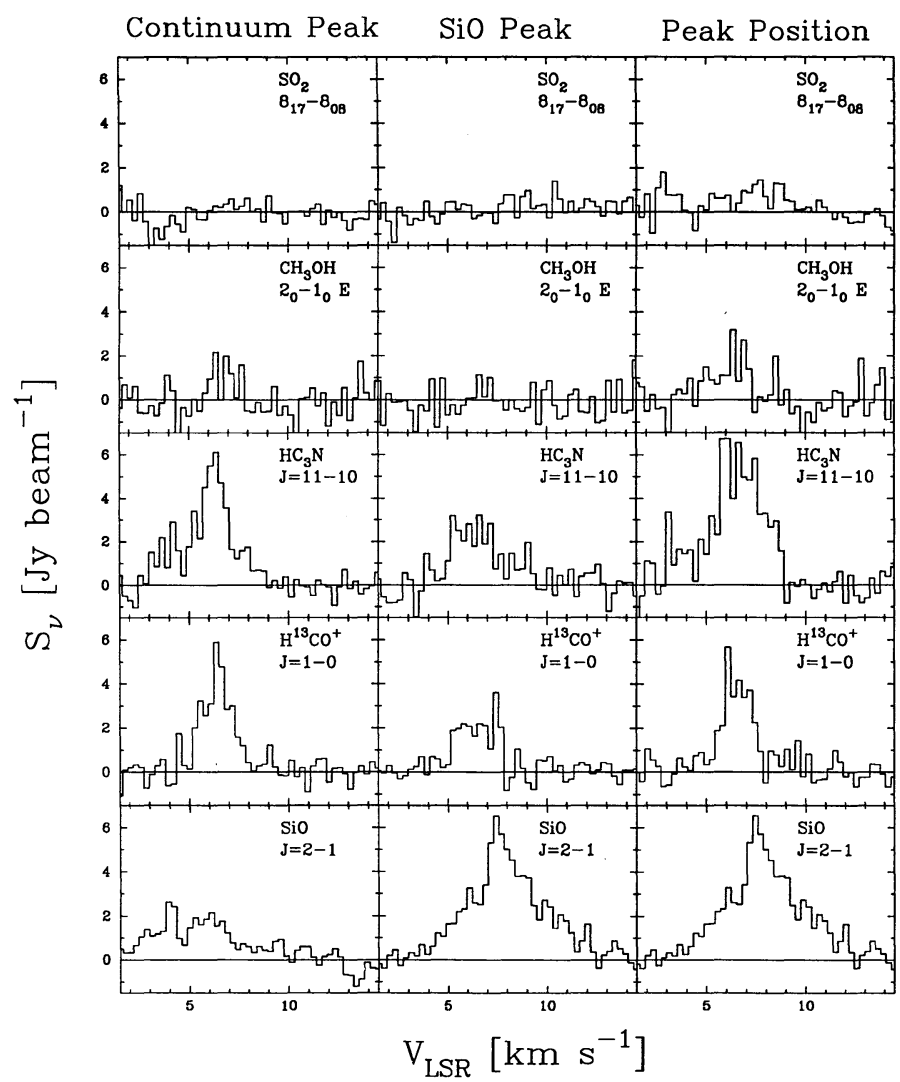

FIG. 2. - Spectra of each of the detected molecules. Spectra are taken at the location of the continuum source (left column), at the position of the SiO peak (middle column), and at the peak position for each molecule (right column).

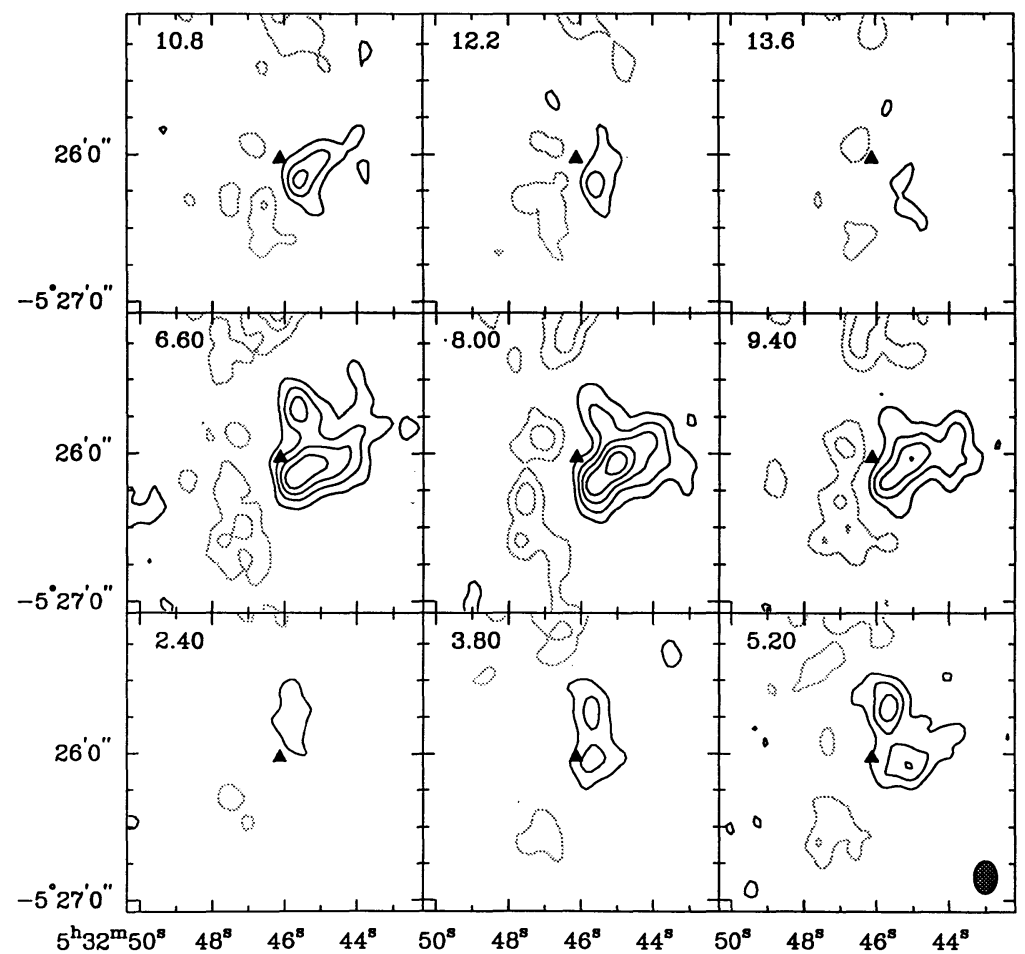

FIG. 3.-Velocity maps of SiO $J=2-1$ emission. Contour intervals are $\pm 1 \mathrm{Jy}_{\text {beam }}^{-1}(2 \sigma)$. The triangle marks the location of the peak continuum emission. The numbers in the upper left corner indicate the $V_{\mathrm{LSR}}$ for each panel. The beam is represented in the lower right of the $V_{\mathrm{LSR}}=5.2 \mathrm{~km} \mathrm{~s}^{-1} \mathrm{panel}$ 


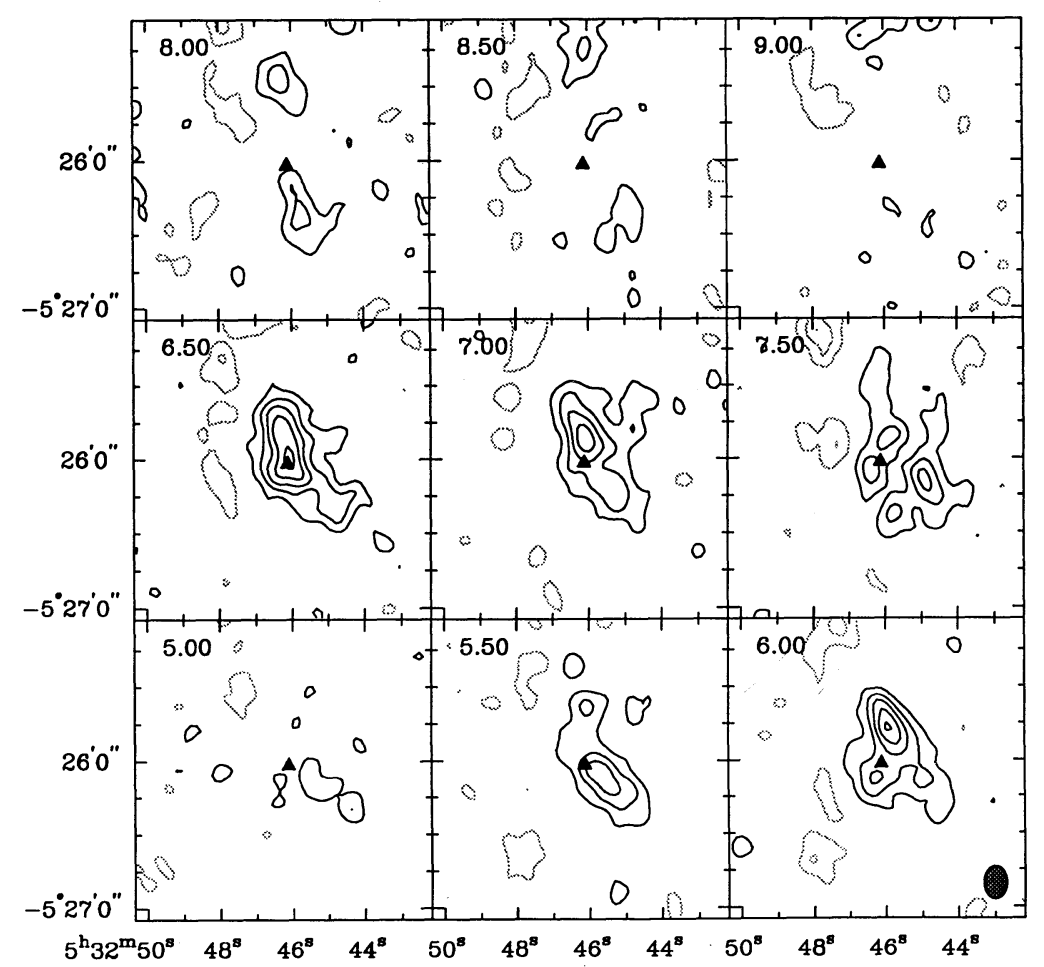

FIG. 4. - Velocity maps of $\mathrm{H}^{13} \mathrm{CO}^{+} J=1-0$ emission. Contour intervals are \pm 1 Jy beam ${ }^{-1}(2 \sigma)$. The triangle marks the location of the peak continuum emission. The numbers in the upper left corner indicate the $V_{\mathrm{LSR}}$ for each panel. The beam is represented in the lower right of the $V_{\mathrm{LSR}}=6.0 \mathrm{~km} \mathrm{~s}^{-1}$ panel.

$V_{\text {lsr }}=6.5 \mathrm{~km} \mathrm{~s}^{-1}$ and the $\mathrm{SO}_{2}$ emission is too weak to yield conclusive velocity information.

\section{STRUCTURE OF THE ORION S REGION}

The large-scale structure in the Orion $\mathrm{S}$ region is best highlighted in a number of previous molecular line observations. Maps of $\mathrm{NH}_{3}$ (Ziurys et al. 1981 and Bartrla et al. 1983), $\mathrm{C}^{18} \mathrm{O}$ (Wilson et al. 1986), $\mathrm{H}_{2} \mathrm{CO}$ (Batrla et al. 1983; Johnston, Henkel, \& Wilson 1984), CS (Mundy et al. 1986) and the largescale dust distribution (Mezger et al. 1990) all show a roughly $0.5 \times 1$ 1'.0 molecular core oriented north-south which forms the southern section of the Orion molecular ridge. Multitransition ammonia observations indicate gas temperatures ranging from $75 \mathrm{~K}$ (Batrla et al. 1983) to as high as $270 \mathrm{~K}$ (Mauersberger et al. 1986) in this gas. Other observations suggest molecular rotation temperatures (Menten et al. 1988; Groesbeck et al. 1993) and dust temperatures (Keene et al. 1982; Werner 1982; Mezger et al. 1990) in the range of 45-65 K. Estimates from the $\mathrm{NH}_{3}$ and $\mathrm{HC}_{3} \mathrm{~N}$ emission, and from the dust continuum, indicate gas densities $\gg 10^{5} \mathrm{~cm}^{-3}$ over $30^{\prime \prime}$ scales.

Our observations concentrate on some of the detailed chemical and physical structures within the overall context of this molecular core. In the following subsections, we will discuss our data and compare them with previous observations of the five molecules being studied. Molecular column densities are derived using the formula

$$
N_{x}=\frac{3 c^{2}}{16 \pi^{3} v^{3}} \frac{Q\left(T_{\mathrm{rot}}\right)}{g_{u}} \frac{\int S_{v} d v}{\left|\mu_{u l}\right|^{2} \Omega_{B}} \exp \left(\frac{E_{u}}{k T_{\text {rot }}}\right),
$$

which assumes optically thin emission and local thermodynamic equilibrium. In this equation, $Q\left(T_{\text {rot }}\right)$ is the partition function, $g_{u}$ is the statistical weight of the upper level, $\Omega_{B}$ is the beam solid angle, $E_{u}$ is the energy of the upper state, $\left|\mu_{u l}\right|$ is the dipole moment matrix element, and $T_{\text {rot }}$ is the rotational excitation temperature. The partition function, energy of the upper state, dipole matrix element, and statistical weights were obtained from the line catalog of Poynter \& Pickett (1984). An excitation temperature of $50 \mathrm{~K}$ is adopted from Menten et al. (1988). Table 3 lists the derived values for the column density of each molecule at various position in the Orion $S$ region. The column densities are underestimates in the cases where there is missing flux due to extended structures. For the maps of $\mathrm{SiO}$ and $\mathrm{HC}_{3} \mathrm{~N}$, we estimate that we are recovering approximately $60 \%$ of the total emission which leads to an underestimate in the column density of these molecules of $\sim 20 \%$, assuming that the missing emission is distributed on scales slightly larger than the maximum measured spacing. A $10 \mathrm{~K}$ uncertainty in rotation temperature leads to a $\sim 15 \%$ uncertainty in our calculated column densities.

\section{1. $\mathrm{SiO}$}

Observations of $\mathrm{SiO} J=2-1$ by Ziurys \& Friberg (1987) gave a $T_{A}^{*}=1.1 \mathrm{~K}$ line with wings extending $\pm 12-15 \mathrm{~km} \mathrm{~s}^{-1}$. This line is distinct from emission associated with IRc 2 both spatially and kinematically $\left(V_{\mathrm{LSR}}=7.8 \mathrm{~km} \mathrm{~s}^{-1}\right)$. More recent observations (Ziurys et al. 1990) have established the bipolarity of the high-velocity $\mathrm{SiO}$ emission, showing a peak $10^{\prime \prime}$ south of Orion $\mathrm{S}$ for the redshift gas and $5^{\prime \prime}$ north of Orion $\mathrm{S}$ for the blueshifted gas. The outflow is characterized by densities $\sim 3 \times 10^{5} \mathrm{~cm}^{-3}$ and may have a kinematic energy as high as $\sim 9 \times 10^{45}$ ergs. The overall size of the region is estimated to be $5^{\prime \prime} \times 10^{\prime \prime}$ for the line center and $15^{\prime \prime} \times 30^{\prime \prime}$ for the wings. Comparing with our observations, we find a good correspondence between both the position of peak emission and the general morphology of the source. Our spectra show emission over a more restricted velocity range, $\sim 14 \mathrm{~km} \mathrm{~s}^{-1}$, but this is 
TABLE 3

Molecular Column Densities

\begin{tabular}{|c|c|c|c|}
\hline Position & $\underset{\left(\mathrm{Jy} \mathrm{beam}{ }^{-1} \mathrm{~km} \mathrm{~s}^{-1}\right)}{\int S d V^{\mathrm{a}}}$ & $\begin{array}{c}N_{x} \\
\left(10^{14} \mathrm{~cm}^{-2}\right)\end{array}$ & Molecule \\
\hline Peak continuum ........ & $\left\{\begin{array}{c}<3.0^{\mathrm{b}} \\
7.2 \\
<2.0^{\mathrm{b}} \\
18.2 \\
6.2 \\
100.0^{\mathrm{c}}\end{array}\right.$ & $\begin{array}{r}<0.4 \\
0.8 \\
<4.3 \\
1.5 \\
86.0 \\
24.8\end{array}$ & $\begin{array}{c}\mathrm{SiO} \\
\mathrm{H}^{13} \mathrm{CO}^{+} \\
\mathrm{SO}_{2} \\
\mathrm{HC}_{3} \mathrm{~N} \\
\mathrm{CH}_{3} \mathrm{OH} \\
\mathrm{CS}\end{array}$ \\
\hline Peak SiO $\ldots \ldots \ldots \ldots \ldots$ & $\left\{\begin{array}{c}10.2 \\
4.2 \\
<2.0^{\mathrm{b}} \\
7.5 \\
<3.0^{\mathrm{b}} \\
65.0^{\mathrm{c}}\end{array}\right.$ & $\begin{array}{r}1.4 \\
0.5 \\
<4.3 \\
0.6 \\
<42 \\
16.1\end{array}$ & $\begin{array}{c}\mathrm{SiO} \\
\mathrm{H}^{13} \mathrm{CO}^{+} \\
\mathrm{SO}_{2} \\
\mathrm{HC}_{3} \mathrm{~N} \\
\mathrm{CH}_{3} \mathrm{OH} \\
\mathrm{CS}\end{array}$ \\
\hline Peak $\mathrm{H}^{13} \mathrm{CO}^{+} \ldots \ldots \ldots$ & $\left\{\begin{array}{c}<3.0^{\mathrm{b}} \\
9.8^{\circ} \\
<2.0^{\mathrm{b}} \\
16.1 \\
<3.0^{\mathrm{b}} \\
70.0^{\mathrm{c}}\end{array}\right.$ & $\begin{array}{c}<0.4 \\
1.1 \\
<6 \\
1.3 \\
<42 \\
17.4\end{array}$ & $\begin{array}{c}\mathrm{SiO} \\
\mathrm{H}^{13} \mathrm{CO}^{+} \\
\mathrm{SO}_{2} \\
\mathrm{HC}_{3} \mathrm{~N} \\
\mathrm{CH}_{3} \mathrm{OH} \\
\mathrm{CS}\end{array}$ \\
\hline Peak $\mathrm{HC}_{3} \mathrm{~N} \ldots \ldots \ldots$ & $\left\{\begin{array}{c}<3.0^{\mathrm{b}} \\
4.0^{\circ} \\
<2.0^{\mathrm{b}} \\
25.2 \\
6.4 \\
80.0^{\mathrm{c}}\end{array}\right.$ & $\begin{array}{r}<0.4 \\
0.5 \\
<6 \\
2.1 \\
89.0 \\
20.0\end{array}$ & $\begin{array}{c}\mathrm{SiO} \\
\mathrm{H}^{13} \mathrm{CO}^{+} \\
\mathrm{SO}_{2} \\
\mathrm{HC}_{3} \mathrm{~N} \\
\mathrm{CH}_{3} \mathrm{OH} \\
\mathrm{CS}\end{array}$ \\
\hline Peak $\mathrm{CH}_{3} \mathrm{OH} \ldots \ldots \ldots$ & $\left\{\begin{array}{c}5.0 \\
6.1 \\
<2.0^{\mathrm{b}} \\
22.0 \\
9.2 \\
100.0^{\mathrm{c}}\end{array}\right.$ & $\begin{array}{r}0.7 \\
0.7 \\
<6 \\
1.8 \\
128.0 \\
24.8\end{array}$ & $\begin{array}{c}\mathrm{SiO} \\
\mathrm{H}^{13} \mathrm{CO}^{+} \\
\mathrm{SO}_{2} \\
\mathrm{HC}_{3} \mathrm{~N} \\
\mathrm{CH}_{3} \mathrm{OH} \\
\mathrm{CS}\end{array}$ \\
\hline Peak $\mathrm{SO}_{2} \ldots \ldots \ldots \ldots$ & $\left\{\begin{array}{c}<3.0^{\mathrm{b}} \\
<2.0^{\mathrm{b}} \\
3.8 \\
14.5 \\
4.3 \\
70.0^{\mathrm{c}}\end{array}\right.$ & $\begin{array}{r}<0.4 \\
<0.2 \\
8.2 \\
1.2 \\
59.9 \\
17.4\end{array}$ & $\begin{array}{c}\mathrm{SiO} \\
\mathrm{H}^{13} \mathrm{CO}^{+} \\
\mathrm{SO}_{2} \\
\mathrm{HC}_{3} \mathrm{~N} \\
\mathrm{CH}_{3} \mathrm{OH} \\
\mathrm{CS}\end{array}$ \\
\hline
\end{tabular}

a Emission in an $11^{\prime \prime} \times 6$ " beam

b $2 \sigma$ upper limits.

c Based on data from Mundy et al. 1988, 7".5 beam.

likely to be due to lack of sensitivity. We derive a $\mathrm{SiO}$ column density of $1.4 \times 10^{14} \mathrm{~cm}^{-2}$ at the position observed by Ziurys $\&$ Friberg (1987). This value is consistent with their measurements after correcting for the difference in assumed rotation temperature and beam size.

\section{2. $\mathrm{HC}_{3} \mathrm{~N}$ and $\mathrm{H}^{13} \mathrm{CO}^{+}$}

$\mathrm{HC}_{3} \mathrm{~N} J=12-11$ emission from the Orion $\mathrm{S}$ region shows a high-density condensation with a modest velocity width (Martin-Pintado et al. 1990). In these maps, the $\mathrm{HC}_{3} \mathrm{~N}$ emission is extended, particularly north along the quiescent molecular ridge. The morphology of the $J=12-11$ maps is consistent with the structure in our $J=11-10$ maps and reveals the large-scale structure causing the negative features in our map. The position of peak emission in our map is consistent with that of Martin-Pintado et al. (1990). The peak column density derived for $\mathrm{HC}_{3} \mathrm{~N}, \mathrm{~N}\left(\mathrm{HC}_{3} \mathrm{~N}\right)$, is $2.1 \times 10^{14}$ $\mathrm{cm}^{-2}$. As is evident from Figure 1 , the $\mathrm{HC}_{3} \mathrm{~N}$ emission is more extended than the emission from the other four molecules. Its column density varies only by a factor of 3 over the positions given in Table 3.
The emission distribution of $\mathrm{H}^{13} \mathrm{CO}^{+}$is very similar to that of $\mathrm{HC}_{3} \mathrm{~N}$. $N\left(\mathrm{H}^{13} \mathrm{CO}^{+}\right)$ranges from nearly equal to $N\left(\mathrm{HC}_{3} \mathrm{~N}\right)$ to a factor of 4 less. There are no previous estimates of $N\left(\mathrm{H}^{13} \mathrm{CO}^{+}\right)$toward Orion $\mathrm{S}$ but, from the negative features in our integrated maps, we expect that there is larger scale structure in the emission; consequently, the true $N\left(\mathrm{H}^{13} \mathrm{CO}^{+}\right)$may be somewhat higher.

\section{3. $\mathrm{CH}_{3} \mathrm{OH}$}

An extensive study of methanol emission in the Orion-KL region was performed by Menten et al. (1988). Spectra of a number of transitions in the $3 \mathrm{~mm}$ window seem to be best fit by two velocity components, a broad redshifted wing and the main $3 \mathrm{~km} \mathrm{~s}^{-1}$ wide line, similar to the $\mathrm{NH}_{3}$ observations of Batrla et al. (1983). A map of the $5_{-1}-4_{0} E$ emission shows a sharp peak near Orion $S$ similar to our $20_{0}-1_{0} E$ map. Menten et al. (1988) interpret the emission peak as a real enhancement in $\mathrm{CH}_{3} \mathrm{OH}$ abundance, driven by internal heating from an embedded source. They estimate $\mathrm{N}\left(\mathrm{CH}_{3} \mathrm{OH}\right) \sim 3 \times 10^{16}$ $\mathrm{cm}^{-2}$ which is similar to the value derived by Groesbeck et al. $\left(1993 ; N\left(\mathrm{CH}_{3} \mathrm{OH}\right)=2.5 \pm 0.3 \times 10^{15} \mathrm{~cm}^{-2}\right.$ for $T_{\text {rot }}=45 \pm 2$ $\mathrm{K})$. These values are consistent with our peak column density after correcting for a smaller source size. Column densities derived at most other positions are only upper limits.

\section{4. $\mathrm{SO}_{2}$}

Sulfur dioxide has been detected from the Orion $\mathrm{S}$ region in the $3_{13}-2_{02}$ transition by Irvine, Good, $\&$ Schloerb (1983) and in the $8_{17}-8_{08}$ transition by Ziurys (1992). Observations by Groesbeck et al. (1993) have detected a number of $\lambda=0.87 \mathrm{~mm}$ $\mathrm{SO}_{2}$ transitions toward Orion $\mathrm{S}$ using the Caltech Submillimeter Observatory (CSO). A rotation diagram fit to these spectra yields $T_{\text {rot }}=75 \pm 6 \mathrm{~K}$ and $N\left(\mathrm{SO}_{2}\right)=1.9 \pm 0.3 \times 10^{14}$ $\mathrm{cm}^{-2}$. The BIMA data yield a peak $\mathrm{SO}_{2}$ column density of $8 \times 10^{14} \mathrm{~cm}^{-2}$, consistent with the CSO results after correcting for beam dilution.

\subsection{Dust Continuum}

Continuum emission from millimeter through far-infrared wavelengths (Mundy et al. 1986; Mezger et al. 1990; Keene et al. 1982; Drapatz et al. 1983) indicates the presence of a warm, compact dust source in the Orion $\mathrm{S}$ region. Fits to the highest resolution data (Mezger et al. 1990; Mundy et al. 1986) yield a dust temperature of $65 \mathrm{~K}$ and a source size of roughly $12^{\prime \prime} \times 7^{\prime \prime}$. Our peak and total continuum fluxes and source size (deconvolved source size of $11^{\prime \prime} \times 7^{\prime \prime}$ ) are very similar to previous $\lambda=3.1 \mathrm{~mm}$ interferometric observations (Mundy et al. 1986). Assuming a dust temperature of $65 \mathrm{~K}$, a mass opacity coefficient of $10 \mathrm{~g} \mathrm{~cm}^{-2}$ at $\lambda=250 \mu \mathrm{m}$ (Hildebrand 1983), and a wavelength dependence of $\lambda^{-2}$ for the dust emissivity, the mass in the compact interferometer source is $\sim 56 M_{\odot}$. If instead a $\lambda^{-1}$ wavelength dependence is used, as suggested for optically visible young stellar objects (YSOs) by Beckwith et al. (1990), the mass reduces to $4.5 M_{\odot}$; however, this estimate is likely to be unrealistically low for Orion $\mathrm{S}$ since Wright et al. (1992) find wavelength dependences from $\lambda^{-1.5}$ to $\lambda^{-2}$ for embedded sources in the Orion IRc 2 region. When the same assumed dust properties are applied to single-dish continuum data (Schloerb et al. 1987; Mezger et al. 1990), the overall molecular core associated with Orion $\mathrm{S}$ has a mass of $\sim 280$ $M_{\odot}$. Thus, the compact source contains about $\frac{1}{5}$ of the mass in the region. 


\section{CHEMISTRY OF THE ORION S REGION}

\subsection{Interpretation of Molecular Column Densities}

Interpretation of the molecular distributions in star-forming regions is problematic. As seen in Figure 1, the Orion $\mathrm{S}$ region, like the Orion IRc 2 region, exhibits different morphologies in various molecular transitions, even when these transitions should trace regions with similar densities and temperatures. In order to study these variations, we compare column densities of the observed molecules at the different peak positions. Since $\mathrm{HC}_{3} \mathrm{~N}$ is the most extended of the distributions and is also seen to be relatively constant over a range of physical conditions (Blake et al. 1987), we will use $\mathrm{HC}_{3} \mathrm{~N}$ as an internal standard to measure relative enhancements or depletions of other species. We also compare to the CS observations of Mundy et al. (1986; Fig. 2). CS is expected to be insensitive to the presence of shocks or high-temperature chemistry and has abundances in active regions which are well fitted by models (Hartquist, Oppenheimer, \& Dalgarno 1980; Prasad \& Huntress 1982; Blake et al. 1987). We find $N(\mathrm{CS}) / N\left(\mathrm{HC}_{3} \mathrm{~N}\right)$ ranges from 10 to 27 , although the CS emission may have an optical depth greater than 1 .

Table 4 lists the ratios of the molecular column density to $N\left(\mathrm{HC}_{3} \mathrm{~N}\right)$ for the different peak positions, for TMC-1 and various components of IRc 2 . On average, $N\left(\mathrm{HC}_{3} \mathrm{~N}\right)$ at the peak positions is comparable to that in the Orion IRc 2 extended ridge component. The $\mathrm{H}^{13} \mathrm{CO}^{+}$column density ratio varies by about a factor of 4 over the peak positions. Since the observed transitions have similar critical densities, this ratio suggests that the abundances of these molecules are fairly constant. Because $\mathrm{H}^{13} \mathrm{CO}^{+}$is dependent on the gas fractional ionization, models predict a decrease in its abundance in the denser portions of clouds at constant temperature if grains are ignored (Iglesias \& Silk 1978). In centrally condensed sources, models incorporating both gas-phase and grain mantle chemistry predict a flat or slightly increasing $\mathrm{H}^{13} \mathrm{CO}^{+}$abundance with density due to molecular depletion (Rawlings et al. 1992). $\mathrm{HC}_{3} \mathrm{~N}$ is expected to be abundant in dense regions and to show some enhancement toward higher temperature regions. In Orion $\mathrm{KL}, \mathrm{H}^{13} \mathrm{CO}^{+}$is associated solely with the quiescent material, while $\mathrm{HC}_{3} \mathrm{~N}$ is observed in all but the compact ridge component and is most abundant toward the hot core and plateau components (Blake et al. 1987). Recently, observations have shown that ions such as $\mathrm{HCO}^{+}$and $\mathrm{H}_{3} \mathrm{O}^{+}$may be more robust than previously thought (Phillips, van Dishoeck, \& Keene 1992); this may explain the apparent cohabitation of $\mathrm{H}^{13} \mathrm{CO}^{+}$and $\mathrm{HC}_{3} \mathrm{~N}$ in Orion $\mathrm{S}$.

The $\mathrm{SiO}$ column density varies significantly with respect to $\mathrm{HC}_{3} \mathrm{~N}$, with the strongest enhancement offset from the contin-

TABLE 4

Column Density Ratio: $N_{x} / N_{\mathrm{HC}_{3} \mathrm{~N}}$

\begin{tabular}{|c|c|c|c|c|c|}
\hline Position & $\mathrm{SiO}$ & $\mathrm{H}^{13} \mathrm{CO}^{+}$ & $\mathrm{CH}_{3} \mathrm{OH}$ & $\mathrm{SO}_{2}$ & $\mathrm{CS}$ \\
\hline Continuum peak & $<0.3$ & 0.5 & 57 & $<2.9$ & 17 \\
\hline SiO peak .......... & 2.3 & 0.8 & $<70$ & $<7.2$ & 27 \\
\hline $\mathrm{H}^{13} \mathrm{CO}^{+}$peak $\ldots \ldots \ldots \ldots$ & $<0.3$ & 0.9 & $<32$ & $<3.3$ & 13 \\
\hline $\mathrm{CH}_{3} \mathrm{OH}$ peak $\ldots \ldots \ldots \ldots$ & 0.4 & 0.4 & 71 & $<2.4$ & 14 \\
\hline $\mathrm{HC}_{3} \mathrm{~N}$ peak $\ldots \ldots \ldots \ldots$ & $<0.3$ & 0.2 & 42 & $<2$ & 10 \\
\hline $\mathrm{SO}_{2}$ peak $\ldots \ldots \ldots \ldots \ldots$ & $<0.3$ & $<0.2$ & 50 & 6.8 & 15 \\
\hline TMC-1 $\ldots \ldots \ldots \ldots \ldots \ldots$ & $<0.0003$ & 0.75 & 0.33 & $<0.2$ & 1.7 \\
\hline Orion IRc 2 hot core $\ldots .$. & $\ldots$ & $<0.009$ & $77-769$ & $<15.4$ & $>7.7$ \\
\hline Orion IRc 2 ridge $\ldots \ldots \ldots$ & $<2.5$ & 0.20 & 75 & $<25.0$ & 18.8 \\
\hline Orion IRc 2 plateau ..... & 0.9 & $\ldots$ & $\ldots$ & 17.3 & 0.6 \\
\hline
\end{tabular}

uum source. Chemical models predict that both high temperatures and shocks can produce enhancements in the gas-phase $\mathrm{SiO}$ abundance. On the basis of the abundance ratio of $\mathrm{SiO}$ to HCN in several molecular clouds, Ziurys et al. (1989) deduced that $\mathrm{SiO}$ is formed by endothermic reactions with activation barriers around $90 \mathrm{~K}$. Langer \& Glassgold (1990) produced a model which explains the sensitivity of $\mathrm{SiO}$ to high density and temperature as the dependence of the rate coefficients on the population of the excited fine-structure levels of the neutral $\mathrm{Si}$ atom. However, observations of lowtemperature star-forming regions with $\mathrm{SiO}$ emission question this relationship (Bachiller, Menten, \& del Rio-Alvarez 1990; Bachiller, Martin-Pintado, \& Fuente 1991). Martin-Pintado, Bachiller, \& Fuente (1992) suggest a shock-formation mechanism in which grains are disrupted by a shock, thereby releasing $\mathrm{Si}$ into the gas phase allowing $\mathrm{SiO}$ to form via ion-molecule reactions or shock chemistry. Based on the displaced position of the $\mathrm{SiO}$ peak with respect to the continuum source (and presumed heat source), we favor a shock origin for the $\mathrm{SiO}$ emission in Orion $\mathrm{S}$. The $\mathrm{SiO}$ emission then traces regions where the outflow strongly interacts with the ambient cloud material. The peak fractional abundance of $\mathrm{SiO}$ is $\sim 10^{-10}$ which represents a very small fraction of the cosmic $\mathrm{Si}$ abundance $\left(3 \times 10^{-5}\right)$; hence, only a small amount of grain disruption is needed.

The weak $\mathrm{SO}_{2}$ emission associated with Orion $\mathrm{S}$ is located along the southeast edge of the $\mathrm{SiO}$ emission, near the $\mathrm{HC}_{3} \mathrm{~N}$ peak. The chemistry responsible for $\mathrm{SO}_{2}$ is thought to be quite distinct from that for SiO. For example, in Orion IRc 2, the $\mathrm{SO}_{2}$ is mainly seen in the extended "doughnut" while the $\mathrm{SiO}$ is concentrated near IRc 2 (Plambeck 1988; Wright et al. 1983). $\mathrm{SO}_{2}$ has been observed toward both quiescent and active starforming regions, unlike SiO (Irvine et al. 1983; Ziurys et al. 1989). Chemical models predict that $\mathrm{SO}_{2}$ and $\mathrm{SiO}$ should behave differently in response to shocks, $\mathrm{SO}_{2}$ being strongly enhanced in C-type shocks and only moderately affected by J-type shocks while the opposite trend is predicted for $\mathrm{SiO}$ (Mitchell 1984; Neufeld \& Dalgarno 1989). Thus, the high $N\left(\mathrm{SO}_{2}\right)$ in Orion $\mathrm{KL}$ may be explained as a slow shock from the low-velocity plateau gas (Blake et al. 1987), while other sources (e.g., L1448; Bachiller et al. 1990) have smaller $\mathrm{SO}_{2}$ column densities due to very high velocity, J-type shocks. Similarly, Orion S may be explained as having outflow conditions more favorable to formation of $\mathrm{SiO}$ than to $\mathrm{SO}_{2}$.

The weakness of $\mathrm{SO}_{2}$ could also be seen as an indicator of the relative youth of Orion S compared to Orion IRc 2. SO is made fairly directly from $\mathrm{S}$ and $\mathrm{O}_{2}$ or $\mathrm{OH}$. $\mathrm{SO}_{2}$ is then produced from SO by reactions again with $\mathrm{OH}$. Steady state models predict roughly equal amounts of $\mathrm{SO}$ and $\mathrm{SO}_{2}$ as seen in the hot core of Orion-KL. However, if the abundances are growing due to grain evaporation or shattering, the $\mathrm{SO}_{2}$ abundance lags behind that of SO. Strong detections of several transitions of SO in Orion S (Groesbeck et al. 1993) leave open such a possibility. A simple kinetic model run at densities of $n_{\mathrm{H}_{2}}=10^{6} \mathrm{~cm}^{-3}$ and $T_{\text {kinetic }}=50 \mathrm{~K}$ predicts that the production of $\mathrm{SO}_{2}$ from $\mathrm{SO}$ takes approximately $10^{4} \mathrm{yr}$. This scenario could also explain the morphology of the IRc 2 region where atomic Si (Haas, Hollenback, \& Erickson 1991) and SiO are concentrated on IRc 2 and tracing the recently shocked gas while $\mathrm{SO}$ and $\mathrm{SO}_{2}$ are more extended and trace the more evolved shocked gas.

The ratio of $N\left(\mathrm{CH}_{3} \mathrm{OH}\right) / N\left(\mathrm{HC}_{3} \mathrm{~N}\right)$ is fairly constant over the region detected in methanol. The $\mathrm{CH}_{3} \mathrm{OH}$ emission, like 
$\mathrm{H}^{13} \mathrm{CO}^{+}$and $\mathrm{HC}_{3} \mathrm{~N}$, peaks at a $V_{\mathrm{LSR}}$ of $\sim 6.5 \mathrm{~km} \mathrm{~s}^{-1}$ suggesting a correspondence between these molecules. $\mathrm{CH}_{3} \mathrm{OH}$ is now thought to be an abundant component of grain mantles, which when gently evaporated can lead to gas-phase enhancements (Charnley et al. 1990; Millar, Herbst, \& Charnley 1991). The grain mantle composition and evaporation requirements for methanol emission appears spatially confined and hence may not arise from the bulk of the gas traced by $\mathrm{H}^{13} \mathrm{CO}^{+}$and $\mathrm{HC}_{3} \mathrm{~N}$. However, the large partition function for $\mathrm{CH}_{3} \mathrm{OH}$ limited our ability to detect weaker, wide-spread emission.

Overall, it appears that Orion $\mathrm{S}$ has not yet modified local molecular abundances as strongly as IRc 2 . The potential coexistence of species from presumedly different chemistries, for example $\mathrm{CH}_{3} \mathrm{OH}$ and $\mathrm{HC}_{3} \mathrm{~N}$, may indicate that Orion $\mathrm{S}$ is beginning to alter the composition of the surrounding gas. The localization of the $\mathrm{SiO}$ emission away from the continuum source suggest that the Orion $\mathrm{S}$ outflow is beginning to disrupt the surrounding molecular core. The lack of strong $\mathrm{SO}_{2}$ and $\mathrm{CH}_{3} \mathrm{OH}$ emission associated with the $\mathrm{SiO}$ emission suggests that $\mathrm{SiO}$ is tracking a strong shock front.

\subsection{Molecular Fractional Abundances and Comparisons with Other Regions}

In this section, we derive fractional abundances, $N(x) / N\left(\mathrm{H}_{2}\right)$, for the observed molecular species and compare them to abundances in other regions. The fractional abundances are derived for the position of $\lambda=3.1 \mathrm{~mm}$ continuum peak and for a position $12^{\prime \prime}$ to the north along the molecular ridge which should represent the local quiescent cloud. At the $\lambda=3.1 \mathrm{~mm}$ continuum peak, all maps were convolved to a $11^{\prime \prime} \times 6^{\prime \prime}$ beam and the $\mathrm{H}_{2}$ column density was calculated from the continuum flux, $430 \mathrm{mJy} \mathrm{beam}^{-1}$, using the relation of Hildebrand (1983) with a wavelength scaling of $\lambda^{-2}$, yielding $N\left(\mathrm{H}_{2}\right)=8 \times 10^{24}$ $\mathrm{cm}^{-2}$. For the position $12^{\prime \prime}$ north, the $\lambda=1.3 \mathrm{~mm}$ continuum data of Mezger et al. (1991) were used to estimate $N\left(\mathrm{H}_{2}\right)$ using the same opacity relation, yielding $N\left(\mathrm{H}_{2}\right)=2 \times 10^{24} \mathrm{~cm}^{-2}$. The molecular emission at the north position was smoothed over a $11^{\prime \prime}$ beam to match the resolution of the $\lambda=1.3 \mathrm{~mm}$ data. The results are shown in Table 5. Flatter wavelength scaling would lead to higher molecular abundances in all cases.

Based on the data in Table 5, the molecular abundances in the compact component of Orion $\mathrm{S}$ appear to be depleted. The molecular column densities of $\mathrm{HC}_{3} \mathrm{~N}$ and $\mathrm{H}^{13} \mathrm{CO}^{+}$show increases of $\leq 40 \%$ toward Orion $\mathrm{S}$ while the $\mathrm{H}_{2}$ column density increases by a factor of 4 ; hence, averaged over the line of sight, the gas-phase abundances appear to drop by at least a factor of 3 . If the quiescent cloud column density along the line of sight to Orion $\mathrm{S}$ is the same as for the northern position, the data require even larger depletions in the gas associated with Orion S. A possible alternative is that the molecular emission is optically thick and therefore insensitive to column density. In the case of the CS emission, Mundy et al. (1988) argued that the peak brightness temperature of the line was consistent with optically thick emission. In the current observations, the $\mathrm{HC}_{3} \mathrm{~N}$ and $\mathrm{H}^{13} \mathrm{CO}^{+}$lines show peak brightness temperatures of $12.5 \mathrm{~K}$ and $8.0 \mathrm{~K}$, respectively, compared to the adopted rotational temperature of $50 \mathrm{~K}$ and the observed peak brightness temperature of $34 \mathrm{~K}$ in CS $J=2-1$. Given that the density in this region is $\sim 10^{6} \mathrm{~cm}^{-3}$, it is likely that the $\mathrm{HC}_{3} \mathrm{~N}$ and $\mathrm{H}^{13} \mathrm{CO}^{+}$transitions are optically thin. Measurement of depletion in $\mathrm{CH}_{3} \mathrm{OH}$ is limited by the upper limits on the column density toward the north position; $\mathrm{SiO}$ and $\mathrm{SO}_{2}$ were not detected at either position.

The most obvious indication of the depletion is the lack of strong peaks in the molecular emission associated with the Orion $\mathrm{S}$ continuum source in uniform-weighted maps. Uniform-weighted maps of $\mathrm{HC}_{3} \mathrm{~N}$ and $\mathrm{H}^{13} \mathrm{CO}^{+}$show emission of $2.6 \mathrm{Jy} \mathrm{beam}^{-1}$ and $4.5 \mathrm{Jy} \mathrm{beam}^{-1}$ at the position of the continuum source. Calculating the column densities as before, $N\left(\mathrm{H}_{2}\right)$ is $1.1 \times 10^{25} \mathrm{~cm}^{-2}$ in the $7^{\prime \prime} \times 5^{\prime \prime}$ beam and the molecular fractional abundances in the smaller beam are $4 \times 10^{-12}$ and $9 \times 10^{-12}$, for $\mathrm{HC}_{3} \mathrm{~N}$ and $\mathrm{H}^{13} \mathrm{CO}^{+}$, respectively; down by a factor of 5-10 from the $12^{\prime \prime}$ north position. This finding of molecular depletion is consistent with a growing body of evidence for gas-phase depletions in dense regions (Mauersberger et al. 1992; Blake, van Dishoeck, \& Sargent 1992).

Fractional abundances for the Orion IRc 2 hot core and extended ridge components, and for TMC 1-S are also given in Table 5. Examining the fractional abundances, the values for Orion $\mathrm{S}$ fall closer to those for the Orion IRc 2 ridge and 12" north position than to either the Orion hot core or TMC 1-S. The abundances for the Orion IRc 2 extended ridge and $12^{\prime \prime}$ north position are reasonably similar, suggesting an overall common chemistry. Compared to this, the various components of IRc 2 show up to two orders of magnitude increases in selected molecular abundances. In contrast, Orion $\mathrm{S}$ shows significant decreases in all measured fractional abundances. Despite the outflow associated with Orion $S$ having comparable dynamical age to that of IRc 2 (Schmid-Burgk et al. 1990), it appears that this outflow, and the associated stellar luminosity, have not yet enhanced local abundances. It can be argued that this is due to the lower stellar luminosity and lower outflow energy associated with Orion $\mathrm{S}$ but many sources with luminosities and outflow energies comparable to or less than Orion $\mathrm{S}$ have significantly altered local abundances (NGC 2071, Goldsmith et al. 1992; L134N, Swade 1989). In fact, the

TABLE 5

Molecular Fractional Abundances ${ }^{\mathrm{a}}:\left[N(\mathrm{X}) / N\left(\mathrm{H}_{2}\right)\right]$

\begin{tabular}{|c|c|c|c|c|c|c|c|c|c|c|}
\hline Species & TMC-1 $^{\mathrm{a}}$ & Reference & $\begin{array}{c}\text { Orion-S } \\
12^{\prime \prime} \mathrm{N}\end{array}$ & Reference & $\begin{array}{c}\text { Orion S } \\
\text { Cont. Peak }\end{array}$ & Reference & $\begin{array}{c}\text { Orion } \\
\text { Hot Core }\end{array}$ & Reference & $\begin{array}{l}\text { Orion } \\
\text { Ridge }^{\mathbf{a}}\end{array}$ & Reference \\
\hline $\mathrm{HC}_{3} \mathrm{~N} \ldots \ldots \ldots \ldots \ldots$ & $6(-9)$ & 1 & $4(-11)$ & 4 & $1(-11)$ & 4 & $1.6(-9)$ & 5 & $1.3(-10)$ & 5 \\
\hline $\mathrm{CS} \ldots \ldots \ldots \ldots \ldots \ldots \ldots$ & $1(-8)$ & 1 & $9(-10)$ & 4 & $3(-10)$ & 4 & $>1(-8)$ & 5 & $2.5(-9)$ & 5 \\
\hline $\mathrm{CH}_{3} \mathrm{OH} \ldots \ldots \ldots \ldots$ & $2(-9)$ & 2 & $<1(-9)$ & 4 & $1(-9)$ & 4 & $0.1-1(-6)$ & 6 & $3(-9)$ & 6 \\
\hline $\mathrm{H}^{13} \mathrm{CO}^{+} \ldots \ldots \ldots \ldots \ldots$ & $9(-11)$ & 1 & $4(-11)$ & 4 & $1(-11)$ & 4 & $<1(-11)$ & 7 & $2.6(-11)$ & 5 \\
\hline $\mathrm{SO}_{2} \ldots \ldots \ldots \ldots \ldots \ldots$ & $<1(-9)$ & 1 & $<2(-10)$ & 4 & $<4(-11)$ & 4 & $<2(-8)$ & 5 & $<3(-9)$ & 5 \\
\hline $\mathrm{SiO}^{2} \ldots \ldots \ldots \ldots \ldots \ldots$ & $<2(-12)$ & 3 & $<2(-11)$ & 4 & $<5(-12)$ & 4 & $\ldots$ & $\ldots$ & $<3(-10)$ & 5 \\
\hline
\end{tabular}

a Abundances based on single-dish observations (except [7] Vogel et al. 1984).

REFERENCES.-(1) Irvine et al. 1987;(2) Friberg et al. 1988; (3) Ziurys et al. 1989; (4) This work; (5) Blake et al. 1987;(6) Menten et al. 1988; (7) Vogel et al. 1984.

Note.-Assumed $N\left(\mathrm{H}_{2}\right)$ was $8 \times 10^{24} \mathrm{~cm}^{-2}$ for the Orion $\mathrm{S}$ continuum peak and $2 \times 10^{24} \mathrm{~cm}^{-2}$ for the $12^{\prime \prime}$ north position. 
$\mathrm{SiO}$ emission is good evidence that the Orion $\mathrm{S}$ outflow is sufficiently energetic to alter the local chemistry but has simply not had sufficient time to bring about broad changes. This, along with the depletions of common molecules, suggests that Orion $\mathrm{S}$ is in an early stage of chemical evolution.

\section{SUMMARY}

The evolution of the chemistry and molecular abundances in gas associated with forming stars is not well-defined at this point. Ideally, we would like to construct a chemical evolution sequence for YSOs based on observable sources. The physical processes that accompany the birth and early evolution of a star modify the chemistry in the surrounding medium through increases in density and temperature and through the injection of energy via stellar winds and photons. By establishing an evolutionary sequence, we can hope to improve our understanding of individual objects and of the overall pattern of physical and chemical evolution in YSOs. Unfortunately, nature is not so compliant as to make the identification of an evolutionary sequence easy. However, there appear to be some chemical signposts which mark stages of development in this evolution.

From the observations presented, Orion $S$ appears to be a young object. The broad $\mathrm{SiO}$ emission signals the presence of energetic outflow activity, while the weak $\mathrm{SO}_{2}$ emission, a molecule which responds more slowly to this activity, probably indicates a relatively recent onset. The weak $\mathrm{CH}_{3} \mathrm{OH}$ emission also suggests youth to the extent that this emission arises from regions of weak outflow interaction; the development of new chemistries driven by the star-forming activity, as in IRc 2, may be underway but is not clearly established. Analysis of the spatial distributions also reveals the absence of strong emission peaks coincident with the continuum source. Derived fractional abundances indicate a substantial depletion of gas-phase material consistent with the early stellar stages being marked by a "freezing" out of molecules onto grains surfaces. Later, as the object interacts with its surroundings, this material is released and gas-phase enhancements occur, as seen in IRc 2. Finally, a comparison of the fractional abundances toward Orion S with nearby "quiescent" regions show greater similarity in abundances with this material than with any of the components of IRc 2, further suggesting an early age for Orion $\mathrm{S}$.

We would like to thank the BIMA staff for their help with the observations. We are also very grateful to the developers of the MIRAD software package, and in particular Jim Morgan $\&$ Peter Teuben for their guidance and patient attention. This work was sponsored by National Science Foundation, grant AST 9100306 and NASA grani NAGW 3066. G. A. B. gratefully acknowledges support from the David and Lucille Packard and Alfred P. Sloan Foundations, along with NASA grant NAGW-2297. Our special thanks to Lucy Ziurys and Ewine van Dishoeck for critical comments and to Mark McCaughrean for discussions of his infrared images.
Bachiller, R., Martin-Pintado, J., \& Fuente, A. 1991, A\&A, 243, L21 Bachiller, R., Menten, K., \& del Rio-Alvarez, S. 1990, A\&A, 236, 461 Batrla, W., Wilson, T. L., Bastien, P., \& Ruf, K. 1983, A\&A, 128, 279 Beckwith, S., Sargent, A., Chini, R., \& Gusten, R. 1990, AJ, 99, 924

Blake, G. A., Sutton, E. C.. Masson, C. R., \& Phillips, T. G. 1987, ApJ, 315, 621

Blake, G. A., van Dishoeck, E. F., \& Sargent, A. I. 1992, ApJ, 391, L99

Charnley, S. B., Dyson, J. E., Hartquist, T. W., \& Williams, D. A. 1990 MNRÁS, 243,405

Drapatz, S., Haser, L, Hofmann, R., Oda, N., \& Iyengar, K. V. K. 1983, A\&A, 128,207

Genzel, R., \& Stutzki, J. 1989, ARA\&A, 27, 41

Goldsmith, P. F., Margulis, M., Snell, R. L., \& Fukui, Y. 1992, ApJ, 385, 522

Groesbeck, T., Phillips, T. G., \& Blake, G. A. 1993, ApJ, in preparation

Hartquist, T. W., Oppenheimer, M., \& Dalgarno, A. 1980, ApJ, 236, 182

Haas, M. R., Hollenback, D., \& Erickson, E. F. 1991, ApJ, 374, 555

Hildebrand, R. H. 1983, QJRAS, 24, 267

Iglesias, E., \& Silk, J. 1978, ApJ, 226, 851

Irvine, W. M., Good, J. C., \& Schloerb, F. P. 1983, A\&A, 127, L10

Johnston, K. J., Henkel, C. \& Wilson, T. L. 1984, ApJ, 285, L85

Keene, J., Hildebrand, R. H., \& Whitcomb, S. E. 1982, ApJ, 252, L11

Langer, W. D., \& Glassgold, A. E. 1990, ApJ, 352, 121

Martin-Pintado, J., Bachiller, R., \& Fuente, A. 1992, A\&A, 254, 315

Martin-Pintado, J., Rodriguez-Franco, A., \& Bachiller, R. 1990, ApJ, 357, L49

Masson, C. R., \& Mundy, L. G. 1988, ApJ, 324, 538

Mauersberger, R., Henkel, C., Wildon, T. L., \& Walmsley, C. M. 1986, A\&A 162,199

Mauersberger, R., Wilson, T. L., Mezger, P. G., Gaume, R., \& Johnston, K. J. 1992, A\&A, 256, 640

McCaughrean, M. J. 1988, Ph.D. thesis, University of Edinburgh

.1992, private communication

Menten, K. M., Walmsley, C. M., Henkel, C., \& Wilson, T. L. 1988, A\&A, 198, 253

Mezger, P. G., Sievers, A., \& Zylka, R. 1991, in IAU Symp. 147, Fragmentation of Molecular Clouds and Star Formation, ed. E. Falgarone, F. Boulanger, \& G. Duvert (Dordrecht: Kluwer), 245

Mezger, P. G., Wink, J. E., \& Zylka, R. 1990, A\&A, 228, 95

Millar, T. J., Herbst, E., \& Charnley, S. B. 1991, ApJ, 369, 147

Minh, Y. C., Ziurys, L. M., Irvine, W. M., \& McGonagle, D. 1990, ApJ, 360, 136

Mitchell, G. F. 1984, ApJ, 287, 655

Mundy, L. G., Scoville, N. Z., Baath, L. B., Masson, C. R., \& Woody, D. P. 1986, ApJ, 304, L51

Mundy, L. G., Cornwell, T. J., Masson, C. R., Scoville, N. Z., Baath, L. B., \& Johansson, L. E. B. 1988, ApJ, 325, 382

\section{EFERENCES}

Neufeld, D. A., \& Dalgarno, A. 1989, ApJ, 340, 869

Phillips, T. G., van Dishoeck, E. F., \& Keene, J. 1992, ApJ, 399, 533

Plambeck, R. L., \& Wright, M. C. H. 1987, ApJ, 317, L101

. 1988, in Molecular Clouds in the Milky Way and External Galaxies ed. R. L. Dickman, R. L. Snell, \& J. S. Young (New York: Springer-Verlag), 182

Poynter, R. L., \& Pickett, H. M. 1984, Submillimeter, Millimeter, and Microwave Spectral Line Catalogue, JPL Pub. 80-23, Rev. 2

Prasad, S. S., \& Huntress, W. T. Jr. 1982, ApJ, 260, 590

Prasad, S. S., Tarafdar, S. P., Villere, K. R., \& Huntress, W. T., Jr. 1987, in Interstellar Processes, ed. D. J. Hollenback \& H. A. Thronson, Jr. (Dordrecht: Reidel), 631

Rawlings, J. M. C., Hartquist, T. W., Menten, K. M., \& Williams, D. A. 1992, MNRAS, 255,471

Rudolph, A \& Welch, W. J. 1992 , ApJ, 395, 488

Schloerb, F. P., Snell, R. L., \& Schwartz, P. R. 1987, ApJ, 319, 426

Schmid-Burgk, J., Densing, R., Krugel, E., Nett, H., Roser, H. P., Schafer, F., \& Schwaab, G. 1989, A\&A, 215, 150

Schmid-Burgk, J., Gusten, R., Mauersberger, R., Schulz, A., \& Wilson, T. L. 1990, ApJ, 362, L25

Swade, D. 1989, ApJ, 345, 828

Ulrich, B. L. 1981, AJ, 86, 1619

van Dishoeck, E. F., Blake, G. A., Draine, B. T., \& Lunine, J. I. 1991, in Protostars and Planets III, ed. E. H. Levy, J. I. Lunine, \& M. S. Matthews (Tucson: Univ. of Arizona Press)

Vogel, S. N., Wright, M. C. H., Plambeck, R. L., \& Welch, W. J. 1984, ApJ, 283, 655

Walmsley, C. M., Hermsen, W., Henkel, C., Mauersberger, R., \& Wilson, T. L. 1987, A\&A, 172, 311

Werner, M. W. 1982, in Symp. on the Orion Nebula to Honor Henry Draper, (NY Acad. Sci. 395, 79)

Wilson, T. L., Serabyn, E., Henkel, C., \& Walmsley, C. M. 1986, A\&A, 158, L1

Wright, M. C. H., Plambeck, R. L., Vogel, S. N., Ho, P. T. P., \& Welch, W. J. 1983, ApJ, 267, L41

Wright, M. C. H., Sandell, G., Wilner, D. J., \& Plambeck, R. 1992, ApJ, submitted

Ziurys, L. M. 1992, private communication

Ziurys, L. M., \& Friberg, P. 1987, ApJ, 314, L49

Ziurys, L. M., Friberg, P., \& Irvine, W. M. 1989, ApJ, 343, 201

Ziurys, L. M., Martin, R. N., Pauls, T. A., \& Wilson, T. L. 1981, A\&A, 104, 288

Ziurys, L. M., Wilson, T. L., \& Mauersberger, R. 1990, ApJ, 356, L25 